\title{
İlişkisel Bir "Dünya" Olarak Sanat ve Nesnenin Yeni Estetik Deneyimde Bozulumu
}

\section{Art As A Relational "World" and The Deterioration of The Object in The New Aesthetic Experience}

\author{
Güncel Önkal ${ }^{1}$ (D)
}

${ }^{1}$ Prof.Dr. Maltepe Üniversitesi, İnsan ve Toplum Bilimleri Fakültesi Felsefe Bölümü,

İstanbul, Türkiye

ORCID: G.Ö. 0000-0002-3302-6691

Sorumlu yazar/Corresponding author: Güncel Önkal,

Maltepe Üniversitesi, Marmara Eğitim Köyü İnsan ve Toplum Bilimleri Fakültesi, Felsefe Bölümü, Maltepe, İstanbul, 34857, Türkiye E-mail/E-posta: guncelonkal@maltepe.edu.tr

Başvuru/Submitted: 17.03.2019

Revizyon Talebi/Revision Requested: 24.03.2019

Son Revizyon/Last Revision Received: 28.03.2019

Kabul/Accepted: 04.04.2019

\section{Atıf/Citation:}

Onkal, Guncel. "iliş̧kisel Bir “Dünya” Olarak Sanat ve Nesnenin Yeni Estetik Deneyimde Bozulumu." Felsefe Arkivi 50 (2019): 9-16. https://doi.org/10.26650/arcp2019-589804

\section{ÖZET}

Sanatın ilerleme ve gelişme düşüncesi kıskacında konumlandırılışı tarihsel olarak onun ideolojik ve ikonolojik tartışma bağlamında nesnesinin konumlandırılışına geri götürülebilir. Sanat nesnesinin estetik deneyimde bozulumu özneden hareketle değil, sanat nesnesinin bir değerlendirme ediminin nesnesi olarak farklı değerlendirme biçimleri arasında sanat dünyasını kurması beklentisi ile ilgilidir. Beğeni yargısı bu noktada ortaya konulamaz, hakkında konuşulamaz, ontolojik ve epistemolojik dayanakları ile ilişkiselliğin sonucu olarak karşımıza çıkar. Deneyimsel tüm aktörleri ile sanat dünyası beğeniye dayanan bir estetik deneyim dünyası değil artık salt deneyimin gelip geçiciliğinin vücut bulmasıdır. Bu çalışmada sanatın ilişkiselliğinin yarattığı yeni sanat dünyasında sanat nesnesinin estetik deneyimde nasıl bozuluma uğratıldığı Shustermancı bakış açısıyla ele alınacaktır.

Anahtar Kelimeler: Mitos, ikonoloji, ideoloji, deneyim, somaestetik

\section{ABSTRACT}

The position of art in its juxtaposition of progress and development can be historically brought back to the position of its object in the context of its ideological and iconological discussion. The distortion of the art object in the aesthetic experience is not about the subject, but about the expectation that the art object establishes the art world among different forms of evaluation as the object of an evaluation act. The jurisdiction of criticism cannot be put forward at this point, and cannot be talked about, as a result of its relevance to its ontological and epistemological bases. With all its experienced actors, the world of art is not a world of aesthetic experience with appreciation. In this study, how the object of art is distorted in aesthetic experience in the new art world created by the relevance of art will be handled from the perspective of Shusterman.

Keywords: Mythos, iconology, ideology, experience, somaesthetics 


\section{Giriş}

Sanat ve ilerleme (progress) birbirleriyle çok bağlantılı kılınabilecek kavramlar değillerdir. Sanatın dayandığı yaratma edimi ve de onun ardında yatan insanın kültürü yaratan ve aktaran bir varlık olduğu önkabulü ilerleme fikrinden çok forma, sürece, tarihselliğe, deneyimin biricikliğine, sembolleştirmeye, yaşamın anlam ve anlamlandırma fenomenlerine göndermede bulunur. Anatoli Yegerov, çağdaş sanatın sorunsallarını incelediği çalışmasında "Sanatta İlerleme Olur mu?" sorusunu bu bağlamda yanıtlamaya çalışır. Ona göre sanatın gerçek hayatı imlediği kadar fantezi ve imgelem dünyasını da imlemesi bu soruya verilebilecek yanıtların genelleştirilemeyeceğini gösterir (Yegerov, 1984:17). Yegerov’a göre sanatta ilerleme ve gelişme birbirinden farklı olarak ele alınmalıdır. Sanat ancak bu nesnel dünyadan tedrici bir özgürleşmenin yarattığı derinlik ve yüceliği insanlığa ilişkin güvenimizin artması ile sonuçlandırmamız durumunda "gelişir". Dolayısıyla "ilerleme” kavramının çağrıştırdığı kapitalist, sanayi/üretim odaklı hedeflerden farklı bir boyut ve anlam dairesinde ancak gelişimin olduğu bir alandır (Yegerov, 1984: 17-18).

Günümüzün sanat olgusuna bakışı Yegerov’un dikkatiçektiği spiritüel bir yükselmeyi içermekte midir? Yoksa, bir olgu olarak sanat, estetik epistemolojik ve ontolojik kaygıların çok da uzağında bambaşka bir "dünya” ya mı evrilmiştir? Eğer estetik sanatın dünyasına karşılık gelmiyorsa halen felsefe açısından ele alınışı nasıl gerçekleşebilir? Bu sorular çerçevesinde, bu çalışmada, gerilimler çağının sanatçısı, kurucu mitosları açısından estetik deneyim ve tasarım süreci açısından hangi etik sorunlarla karşı karşıya bırakıldığımız "ikonolojik estetik" ile "estetiğin ideolojisi” arasındaki bağlantılar göz önüne alınarak tartışılacaktır. Çağdaş estetik tartışmalar odağını özne-nesne iç konuşmasına dayalı bir diyaloğun sonucu olmaktan çok sanat nesnesinin bir ilişkisellik türevi olarak nasıl kabul gördüğü üzerinde bulur. Böylelikle sanat felsefesinin tartışmaları ontolojik ve epistemolojik başlıca kaygılar yerine değer felsefesinin değerlendirmeleri ile kendisini dünyaya açar. Bu noktada nesnenin kendisi de terk edilerek nesne hakkındaki değerlendirmenin göreceliği bir zenginlik olarak öncelenmiştir. Özellikle modern anlayış sonrasında bozuluma uğratılan nesnesi bakımından sanat edimi gücünü konumlandırılmasındaki çeşitlilikten aldığı için değerlendirme etkinliği onun dünyasını kurar. Sanat dünyası tüm aktörleri ile öznenin bireysel estetik kurulumu yerine çoğul ilişkilerin özgün dünyası olarak karşımıza çıkar. Bir yanda ideolojik ve ikonolojik gerilim arasında kendisine yer açmaya çalışan sanat dünyası diğer yanda bu dünya karşısında deneyimi bozuluma uğrayan özne söz konusudur. Dolayısıyla artık sanat dünyası ve estetik deneyim karşı karşıya konumlanmaktadır.

İdeolojik-ikonolojik bir direniş olarak estetik deneyim yeniliği, geçersiz kılma, iblisleştirme, belirsizleştirme, yanılgı ve yoksunluk yaratma, gerçekten kopuş, vb. gibi modernliğin cilalı temalarını yaratıcı edimin değerlendirilmesi sürecinde içselleştirerek yerel olanı evrenselden kopardığ 1 gibi, evrensel olanı da kurucu mitoslarından soyutlamaktadır. Bourdieu'nün altını çizerek temellendirmeye çalıştığı gibi, ideolojik olmanın ötesinde ikonolojik bir direniş halinde perspektifini belirleyen çağdaş sanatsal etkinlikler, kurucu mitosunu yitiren öksüz çocuklar, -Jean Paul Sartre'ın deyimiyle "ilk tasarımlar"- olarak, estetik deneyin felsefi içeriğinden çok ikonolojinin dayandığı ideolojinin çağcıl tasarımları olacaklardır. 
Pierre Bourdieu Sanatın Kuralları adlı çalışmasında, sanatın kurallarının değişen yüzünün felsefi temellerini irdelerken önemli bir tehlikeye dikkat çekmektedir: Estetik deneyin nesneleştirme ve belirleme edimi, yeniden yapılanan sanatın mücadele alanı olarak ideolojik ve bir o kadar da “ikonolojik" boyuta taşınmaktadır (Bourdieu, 2006). İkonolojik sanat etkinliği, yerel ve evrensel arasındaki gerilimden bir adım daha öteye giderek "ikonoklast şiddet"e yani ikonların anlam savaşına yönelmektedir. İdeolojik temellerinin ikonolojik kaygılarla birleşmesiyle, tüketim odaklı bir "nesneleştirme" hareketine dönüşen estetik deney, sanat felsefesinin özünü oluşturan değerler alanına ait kaygıların ötesinde, kültürel erdem unvanını dağıtmakta gücü elinde bulunduran ve çeşitli faraziyelerin yeniden üretildiği bir araçsallaştırma olma tehlikesi/diktası ile karşı karşıyadır.

Özellikle estetik deneyimin belirleyicisi olarak üç öbekteki problemlerin çatışkısından söz edebiliriz. Bunlardan birinci estetik yargı, beğeni, değer, tavır, yönelme, duyarlık/farkındalık kategorilerinin oluşturduğu kavramsal alandır. İkinci karmaşı öbeği başlı başına estetiğin kendisi ve tarihsel-olgusal karşılığı oluşturur. Üçüncü olarak ise evrensel olan ile tikel olanın arasında estetik kaygının mahiyeti yer alır. Bu bağlamı dikkate alarak ilkin değerlendirme sorunsalı olarak çağcıl estetiğin nasıl bir konumda olduğuna, ardından ikincil olarak yeni estetik deneyimin neliğine ve son olarak da somaestetik sanat dünyası kavramının bu çatışkıları aşan bütünleştirici bir olanak olarak değerlendirilip değerlendirilemeyeceğine ilişkin ilişkisel saptamalar ışığında bakılacaktır.

\section{Nesneyi Değerlendirme Sorunsalı Olarak Estetik:}

İnsan felsefesi çalışmaları insanın doğaya fırlatılmış bir canlı olduğu savı üzerinden gelişim göstermiştir. Antropolojik temelli bakışta, insan, doğa ile olan mücadelesinde atıl değil etkin öznedir. İnsan, şekillendirendir; çünkü verili olanı kabul etmez. İnsan, başkaldırandır; doğayı bilmek, anlamak ve hatta aşmak ister. İşte olan insanın bu “aşmak” eğilimi - Tolstoy’un deyişiyle"bir abartı" olarak görülebilecek sanatı müthiş bir değişim, direniş ve yaşam alanı olarak "olanın ötesine geçme” eğiliminde belirler. Böylelikle sanat ve onun zengin estetik içeriği insanın tinsel, kültürel, tarihsel, düşünsel zeminine uygun düşer; dahası insansı olanın dışavurumudur.

"Sanat nedir?" sorusu aslında "yaşam nedir?" sorusuna verilecek yanıtların muhasebesiyle özdeştir (Tolstoy, 2016). Sanat etkinliği, bu karşılıklılık ilişkisi bağlamında insanın edimleri dikkate alındığında aynı zamanda bir mücadele alanıdır. İnsanın etkinlik evreni gibi sanatsal yaratma ve beğeni yolculuğu da çağlar boyunca gözlemlenebileceği gibi durağan değildir. İnsan herşeyin ölçüsü ve fail belirleyicisi olarak, kendisinin dışındaki güzeli de bilmek, hatta onu aşkınlığından yere indirerek kendince belirlemek ister. Sonuçta insanın çevresini kuşatan maddi nesnelerle giriştiği anlamlandırma kavgası maddi olmayan duyuşların dünyasında da koca bir yaşam boyu sürer.

İnsan arayışının ve dönüştürücü etkinliğinin tüm politik çağrışımlarının öncesinde ve de öncelikle ontolojik bir kaygıyla ele almamız gerektiğini, sanat yapıtının kökenini irdeleyen Martin Heidegger'den öğreniyoruz. Heidegger'e göre sanat, eserin sanatçısı ile hem kendi içlerinde hem de karşılıklı ilişki içerisine girdikleri bir özün ifadesidir. Sanatın ne olduğu bu nedenle ancak 
eserin kendisinden hareketle açıklanmalıdır. Eser nasıl bir simgedir? Neyi simgelemektedir? $\mathrm{Bu}$ sorulara yanıt arayan bir çift göz sanat eserinde nesnelerin başkayı ifşa ettiğini, bizi diğer olanlarla karşılaştırdığını da fark edecektir. Sanat nesnelerinin, nesnelerden, nesnelerin diğer nesnelerden farklılığı ögretici ve insanı içine alan bir etkinliktir. Dolayısıyla duvarda asılı bir resim, duvarda asılı bir şapkadan, bir av tüfeğinden farklı bir nesnedir.

Heidegger'e göre var-olan, hakikatini sanat eserinde kendini esere koyar (Heidegger, 2011). "Koymak" burada durdurmak anlamındadır. Nesneyi kendisine simge kılan insanın estetik yönelimini ele alan Panofsky'nin "perspektif” ve "biçimlendirme" üzerine çalışmaları bu durdurmanın felsefesini yapan özgün kaynakları düşün ve sanat tarihinden örneklerle bu nedenle sorgulamaktan yanadır. Yaşamımıza konu olan/olmayan neyi durdurmak, ölümsüzleştirmek, biricik kılmak isteriz? Aynı zamanda bu "durdurma" hareketi, estetik deneyimin dayandığı tercihi ve de dolayısıyla değer verme ve değerlendirme tavrının dışavurumudur.

Estetik nesnede yapılagelen bu durdurma, diğer deyişle hakikati sabitleme, dolayısıyla tarihe yazma edimi direnişin ta kendisidir. Bu nedenle de estetik nesne sadece kendisi için nesne olanlardan ayrılacaktır. Estetik nesne başka nesnelerin nesneliğini anlattığı için nesnedir. Estetik nesne özünde tüm nesneler dünyasının tarihsel izdüşümünü taşıdığı için estetiktir ve her birinden "daha" nesnedir.

Estetik değerlendirmeye tabi tutulan nesnenin önce sanat nesnesi, sonra simge kılınması insanın bireysel deneyiminden kaynaklanıyor gibi gözükse de ontolojik temelleri açısından özne, estetik deneyiminde yalnız değildir. Herbert Marcuse "Özgürlük Üzerine Bir Deneme"sinde estetiğe duyulan ihtiyacın toplumsal içeriğinden ayrı düşünülemeyeceğinin altını çizmektedir:

...estetik ihtiyaçların kendilerine ait toplumsal içerikleri vardır: Bunlar insan organizmasının, aklının ve vücudunun kendi potansiyelini gerçekleştirme boyutuna olan talepleridir ve bu boyut sadece tam da normal işleyişleri nedeniyle bu taleplere uymayan ve onları inkâr eden kurumlara karşı verilen mücadele içerisinde yaratılabilir. Estetik ihtiyaçların radikal toplumsal içeriği, bu ihtiyaçların en temel düzeyde karşılanmaları talebi geniş bir ölçekte grup eylemine dönüştüğü zaman açıkça ortaya çıkar.

Toplumsal içerikli nitelikleri dolayısıyla, estetik biçim, "özgür” bir toplumun şablonu demektir. Bourdieu'nün estetik direnişe yüklediği anlam ise bir yandan Heidegger'in metafizik anlamlandırmalarına diğer yandan da Marcuse’ün üzerinde durduğu özgür form olarak sanat anlayışına geri götürülebilecek ancak onlardan daha fazlasını ifade eden bir boyutu işaret etmektedir. Bourdieu’ya göre sanatın "yeni” kuralları bize yeni bir sanatçı, sanat eseri ve izleyici ilişkisi kurmaktadır. Sanat eseri evrensel olana (ki bu Heideggerci anlamda var-olanın varlık’a doğru açılması demektir) karşı çıkışı üzerinden kurduğu mücadele alanında özgünlüğünü kurmaya çalışırken, sanatçı anlam ile biçim arasındaki ilişkide kurucu mitosları aştıkça kendisini sanatçı ilan etmekte, izleyici ise tüm bu ilişkinin özetinin kendi zihninde çıkarıldığından habersiz ikonlaştırdığı sanat eserlerinin nesneselliğini kaybetmektedir. Marcuse’ün özgür sanat 
deyiminden hareketle özetlersek; Bourdieu tam da Kant’nn üçüncü eleştirisinde duyarlık ile imgelem arasındaki sınırların kaldırılması anlamına gelen üretici yaratıcılığın farkındalığını sanat eserinden alarak imgelemin imge olmaktan fazlasını yani ikon olmasını kastetmektedir. Böylelikle sanat yoluyla üretildiği düşünülen nesne giderek sanatçının ve izleyicinin dolayımından çıkarak bulunduğu tarihsel özgürlük anlayışının metafizik boyutlarında kendisini açar ki bu anlaşılamaz ve aktarılamaz biçimde ikonolojiktir.

Sanat eserlerinin sadece biçim olarak değil ifade ve hatta anlam olarak incelenmesi ikonografinin konusudur. Panofsky’nin aktardığı kadarıyla yetinirsek, ikonografik sanat incelemesi sanat eserinde bize sunulan yapıyı salt bir nesne olarak değil, nesnenin olgusal anlamının da ötesinde daha incelikli ifadesine kadar geri götüren inceleme türüdür. İkonolojik sanat incelemeleri bu bağlamda daha sonraları Theodor Lipps'in "einfühlung” adını verdiği önsezisel iletişime oldukça açıktır. Lipps'in anlayışına göre; eserde keşfedilen içeriğe bağlı içsel anlam olmaktan daha ziyade ikonografik anlam için tema ve kavramların dayandığı ikincil anlamlara da ihtiyacımız vardır. Lakin Panofsky'ye göre bu anlamları bilmek bile doğru ikonografik analizi yapmak için yeterli olmayabilir (Panofsky, 2012). Önemli olan sanat eserinin adeta hermeneutik ve ontolojik koşullarına kadar bizi geri götürebilecek geri planda bir bilgi birikimine sahip olmaktır. Kuşkusuz bu bilgi birikimine eserin izleyicisi konumundaki herkes eşit derecede sahip olamayacağından içeriğe fazlasıyla bağımlı birincil ve doğal anlam uzlaşımsal ikincil anlamın yerini alacaktır. Başka deyişle Panofsky’nin ana hatlarını çizdiği ikonografik inceleme, yorum ile yorum nesnesi ve hatta yorum nesnesi ile yeni (ikinci, üçüncü, dördüncü...) “yeni” yorum etkinliği arasında belli ayrımların da oluşturulması demektir. İkonografik incelemede uzlaşımın garantisi ve yorumların geri gidebileceği nokta geleneğin kendisidir. Dolayısıyla Rönesans resmi Yakınçağın estetik paradigması üzerinden tam anlamıyla değerlendirilemez; değerlendirilirse akronolojik hataya düşülür. Bahsi geçen resmi özünde Rönesans geleneği içerisinde bir ikondur. Ancak buna rağmen ikon olduğuna karar verenler Rönesanslılar değil onlardan hemen sonra gelenler olacaktır. İkonolojik estetik bu anlamıyla şu türden felsefi sorunlara yol açmaktadır:

1. Resimde "şapkasını çıkartan adam"ın centilmenliği onun ikonolojik saptamasıdır. Bu yorum olmaksızın nesnenin olgusal anlamı anlaşılsa bile ifadesi tamamlanmayacaktır. Zaten resimler de şapka çıkarma olayını değil onun ardındaki anlamı kuran eserlerdir.

2. İkonoloji ontolojik olarak, yani ortaya çıkış koşulları açısından biçime karşılık konuyu ele alırken önemi bakımından konuya karşılık gelen biçimi ölümsüzleştirdiği için bilme eylemi eserin ortaya çıkısından önce gelmektedir.

3. İkonolojik estetikte tamamlayıcı unsurların herkes için aynı netlik ve kesinlikte olması gerekir (örneğin elinde bıçak değil tirbuşonu tutan Azizin Bartholomew olamayacağı gibi. Elinde tirbuşonla o ancak bir resimdir ancak Azizin ikonu kılınamaz).

Biçim-içerik-anlam ilişkisellik dairesinde ideolojik tasarım ile ikonolojik deneyim birbirlerine bağlanırlar. Bu bağıntı ortaçağın dünyasında kurulduğu gibi artık gündemimizde yer almaz. Daha farklı ifadeyle ontolojik kökenleri açısından sanat iç tutarlılığını yitirmiş, 
anlamıyla kendisi arasına karşıtlıkları koyarak ilerlemeyi seçmiştir. Yüzyılımızın sanatının uzlaşıların karşısında olmakla kendisini oluşturduğunu ve hatta bu karşı duruşuyla, sanatın da yüzyılımızı oluşturduğunu söyleyebiliriz (Tanilli, 1998:25). İkonolojik-ideolojik direnişe bağlanan yeni deneyim işte tam da bu bağıntının iki ucu arasındaki doğru orantıdır. O halde sanat yeni biçim arayışlarından çok yeni içerik kaygılarının, yeni anlam verme türlerinin, yeni gerçeklik tanımlarının ortasındadır.

Estetik deneyimin yeni kutuplu dünyasında ontolojik temellerine geri döndürülemez "çoğulluğu" içerisinde sanat nesnesi başlı başına sorundur. Buradaki sorun ne sanatın giderek karmaşıklaşan ve kaypaklaşan tanımlarından, akımlarından ne de sanatçının yaratma dünyasında yitime uğramasından kaynaklanır. Asıl sorun sanat nesnesinin estetik deneyimde bozuluşa tabi kilınmasında aramak gerekir.

\section{Estetik Deneyimin Yeni Dünyası: Shusterman’cı Analiz}

Richard Shusterman, en temelde, klasik olarak sayılabilecek özneden nesneye yönelen estetik arayışın yerini üstü kapalı, açık-seçik sayılamayacak bir beğeni salgınının aldığını söyler. Shusterman'ın iyimser tavrı bu kapalı estetik deneyimin kendisinde bir kapanmanın olmadığı, aksine karmaşık ve çoğul algının beğeninin yerini aldığı saptaması ile belirir (Shusterman, 2008:79). Shusterman'c1 yaklaşım deneyimi beğeninin öncesine koyarak süje-obje ikileminin boyutlarını aşmayı hedefler. Ona göre gerçek deneyimi aslında bilinç akışının ifadesi olan yaşamın ta kendisidir. Shusterman, Baumgarten' ın gnoseolojiye dayalı estetik projesinin bugün anladığımız estetik deneyimden çok daha geniş bir biçimde kendilik deneyimine, mükemmeliyetçiliğe dayandığını belirtirken; bir yandan da modern felsefenin deneyim kavramına yüklediği anlamları kapsayamadığı gerçeğinin altını çizer (Shusterman, 1999:300). Baumgarten içsel (inferior) olanın büyülü dünyasında bilimin beğeni deneyimini anlayabilmesinin yollarını açmak isterken estetiğin normatif bir disiplin olarak da hayat bulmasını sağladı. Böylelikle doğal estetik anlayışı çerçevesinde başlayan Baumgarten'cı arayışın felsefenin ve davranış bilimlerinin disiplini olabilme kaygısı ile yoluna devam ettiğini görüyoruz. Shusterman, estetik deneyimin yeni dünyasının bedene ve özel bir duyum tarzı olan aisthesis' e odaklanarak Baumgarten'cı temellerde tartışmalarını sürdüren klasik ve makro estetik yaklaşımlar açısından ele alınamayacak derinlik ve çeşitlilikte ele almayı vadeder (Shusterman, 1999:301-302). Somatik estetik deneyimin tam da ortasında, hem deneyimleyen (I am) hem deneyimlenen (I have) olabilen, kendisini nesneleştirebilen bir öznelliğin dışavurumudur. Bedenin tüm duyum kanalları ile merkeze alınması ve refleksiyona tabi tutulmasıdır (Shusterman, 2008b:7-8).

Shusterman'ın somaestetik yaklaşımı bedeni ve bedenselliği ön plana çıkararak estetiğin çağdaş dünyada alımlanmasında sorun oluşturan iki temel problemi çözmek girişimindedir: Dikkat ve yaratıcılık. Dikkatin Platon ve Aristotles' in algı ve form arasındaki ilişkiye odaklandı̆̆ı, daha sonrasında Ortaçağın tümeller tartışmasında ele alınan iki başlılığın arasında kalmaktan kaynaklandığını ifade ederek; aslında sanat nesnesinin kökeninde böylesi bir ikiliğin yer almadığına dikkati çekmek ister (Shusterman, 1998: 241). Yaratıcılık ise kendisini, somaestetik 
yaklaşımda, sanatın öncesinde değil sonrasında gösteren bir deneyim tarzıdır. Bu nedenle ancak sanat nesnesi ile karşı karşıya kalan, diğer deyişle sanat nesnesinin karşısındaki bedenin "keşfedebileceği” bir deneyim biçimidir. Bir sanat nesnesinin değerlendirilmesinde birbirinden çok ayrı beğeni yargılarına varan farklı bedenlerin durumu (deflationism) bu nedenle göreceliliği değil, birlikteliğin ve idealizasyon sürecinin simgesidir. Sanat dünyası bu nedenle bir metaontoloji dünyasıdır (Shusterman, 1998:243).

\section{Sonuç yerine}

Sonuç olarak Shusterman'ın belirginleştirmeye ve diğer yaklaşımlara göre avantajlarını göstermeye çalıştığı somaestetik yaklaşım yeni dünyanın yeni estetik deneyimini en içten biçimde beğenmeye adaydır. Böylelikle estetik ilişkisellik, kendisini ikonolojik ve ideolojik olmak durumundan kurtardığı gibi, öznelerarasılık problemlerinden de sıyıracaktır. Somaestetik deneyim tarzında ne sanatçının olanı aşmak ne de olanı olduğu gibi göstermek kaygıları bulunacaktır. Gerçeklik ve hakikat gibi epistemolojik kavgaların da öncül belirleyicilerinden sıyrılmış doğallığında estetik duyum bütünüyle kavranan, kendisini bedende nasıl ise öyle gösteren, bu nedenle de çoğul duyguların bireşiminden ilhamla simge ya da anlam değil "deneyim" olmakla yetinen bir haldir. Özne ve nesne ayrımı artık deneyimin kendisi deneyimlendiği için tartışma götürmeyecektir. Resimdeki "şapkasını çıkaran adam” izleyicinin olduğu kadar sanatçının da bedenidir.

Shusterman'cı somaestetik, ikonolojik-ideolojik estetik yaklaşımlarını her ne kadar aşmayı denese de metaestetik çalışmaları içerisinde anlamlı görünen bu gayret "sanat dünyası" bağlamında tam anlamıyla gerçekleştirilebilir değildir. Shusterman’ın gayreti kuşkusuz kuruluşu itibariyle bir metafizik gayrettir. Ancak sanat dünyası günümüzde -Shusterman'ın da üzerine çokça çalıştı̆̆ı- Bourdieu’nun dikkati çektiği biçimiyle aracıların (mediasyon) ve sanat piyasasının araçsallaştırıcı baskısı alıında çok aktörlü ve çok biçimli bir dünyadır. Yine Becker, Heinich, Zolberg, vb. gibi isimlerin sanatın toplumsal bir olgu olarak ele alınmasından doğan zorlukları dile getirdiği çalışmalarında görüleceği gibi sanat artık "sosyolojik estetik" olarak karşımıza çıkmaktadır ve hiçbir sanat felsefecisi bunu göz ardı edemez. Bireyin sanat karşısındaki tavrını, beğeni yargısını, sanat nesnesini değerlendirmesini ele alabilecek estetik yaklaşımların göz ardı edemeyeceği kolektif deneyim bağımlılığı özgürlükçü sanat akımlarını ve sanatın gerçekliğe, olana, şimdi ve burada bulunana direniş gücünü örselemektedir. Beğeninin sanat nesnesinde durdurmak istediği, ortaya koymak istediği hakikat, deneyim değiş-tokuşu içerisinde çoktan yitirilmiş olabilir. Shusterman'ın yeni deneyim biçimi olarak genişletmek istediği estetik deneyimle estetik kopuşlar yeniden kurgulanmak istenmektedir. Sosyal olguların dayandığı deneyim gösteriyor ki, nesnesiz, yoksun bir estetik, deneyimin öznelliğinden dolayı tehlike olarak şimdiye kadar filozoflarca öngörülmemiş olsa da, nesnesini yitirmiş bir deneyim estetiği pekala felsefi sorgulamadan yoksun birakabilir. 


\section{Kaynakça}

Bourdieu, Pierre, Sanatın Kuralları: Yazınsal Alanın Oluşumu ve Yapısı, çev. N. K. Sevil, 2. Baskı, İstanbul: YKY, 2006.

Heidegger, Martin, Sanat Eserinin Kökeni, çev. F. Tepebaşl1, 2. baskı, Ankara: DeKi, 2011.

Marcuse, Herbert, Özgürlük Üzerine Bir Deneme, çev. S. Soysal, İstanbul: Ayrınt1, 2013.

Mitchell, W.J. T., İkonoloji: İmaj, Metin, İdeoloji, çev.H. Arslan, İstanbul: Paradigma,2005.

Panofsky, Erwin. İkonoloji Araştırmaları: Rönesans Sanatında İnsancıl Temalar, (çev. O. Düz), İstanbul: Pinhan, 2012.

Shusterman, Richard, A Disciplinary Proposal, The Journal of Aesthetics and Art Criticism, Vol. 57, No. 3 (Summer, 1999), 299-313.

Shusterman, Richard, "Aesthetic experience: from analysis to eros", Aesthetic Experience (ed. R. Shusterman, A. Tomlin), New York, London: Routledge, 2008a.79-98.

Shusterman, Richard, Body Consciousness: A Philosophy of Mindfulness and Somaesthetics. Cambridge Uni. Press, 2008b.

Tanilli, Server, "Yüzyılımız Sanatta Bir Devrimle Başladı", FelsefeLogos, 1998/3,

Tolstoy, L N., Sanat Nedir? (çev. M. Beyhan) İstanbul: T. İş Bankası Yayınları, 2016.

Yegerov, Anatoli, “The Progress Development of Art: Is there such a thing as progress in art?” Problems of Contemporary Aesthetics içinde, (edts. A.Zis, T. Lyumbimova, M. Ovsyannikov) Moskova: Raduga Pub., 9-48, 1984. 